\title{
Characteristics of Lynch syndrome associated ovarian cancer
}

\author{
Woolderink J.M. ${ }^{\mathrm{a}, \mathrm{l}, *}$, De Bock G.H. ${ }^{\mathrm{b}}$, de Hullu J.A. ${ }^{\mathrm{c}}$, Hollema H. ${ }^{\mathrm{d}}$, Zweemer R.P. ${ }^{\mathrm{e}}$, Slangen B.F.M. ${ }^{\mathrm{f}}$, \\ Gaarenstroom K.N. ${ }^{\mathrm{g}}$, van Beurden M. ${ }^{\mathrm{h}}$, van Doorn H.C. ${ }^{\mathrm{i}}$, Sijmons R.H. ${ }^{\mathrm{j}}$, Vasen H.F.A. ${ }^{\mathrm{k}}$, Mourits M.J.E. ${ }^{1}$ \\ a Department of Gynecology, Martini Hospital Groningen, The Netherlands \\ ${ }^{\mathrm{b}}$ Department of Epidemiology, University of Groningen, University Medical Center Groningen, Groningen, The Netherlands \\ ${ }^{c}$ Department of Obstetrics and Gynecology, Radboud University Medical Center, Nijmegen, The Netherlands \\ d Department of Pathology, University of Groningen, University Medical Center Groningen, Groningen, The Netherlands \\ e Department Gynecological Oncology, UMC Utrecht Cancer Center, Utrecht, The Netherlands \\ ${ }^{\mathrm{f}}$ Department of Obstetrics and Gynecology, GROW School for Oncology and Developmental Biology, Maastricht University Medical Center, Maastricht, The Netherlands \\ g Department of Gynecology, Leiden University Medical Center, Leiden, The Netherlands \\ ${ }^{\mathrm{h}}$ Department of Gynecology, The Netherlands Cancer Institute, Amsterdam, The Netherlands \\ ${ }^{i}$ Department of Gynecology, Erasmus MC Cancer Institute, Rotterdam, The Netherlands \\ j Department of Genetics, University of Groningen, University Medical Center Groningen, Groningen, The Netherlands \\ ${ }^{\mathrm{k}}$ Department of Gastroenterology \& Hepatology, Leiden University Medical Center, Leiden, The Netherlands \\ ${ }^{1}$ Department of Gynecologic Oncology, University of Groningen, University Medical Center Groningen, Groningen, The Netherlands
}

\section{H I G H L I G H T S}

- Ovarian cancer in women with LS develops at an early age, with a wide age-range of onset and at an early stage.

- These LS associated ovarian cancers most often has an endometrioid or serous type histology with a good overall survival.

- The early stage of ovarian cancer, in women with LS, could not be attributed to annual gynecological surveillance.

\section{A R T I C L E I N F O}

\section{Article history:}

Received 6 February 2018

Received in revised form 27 March 2018

Accepted 28 March 2018

Available online 5 June 2018

\section{Keywords:}

Lynch syndrome

Ovarian cance

Surveillance

Survival

\section{A B S T R A C T}

Objective. To describe clinical characteristics of Lynch syndrome associated ovarian cancer and the efficacy of surveillance in the early detection of these ovarian cancers.

Methods. All Lynch syndrome associated ovarian cancer cases identified in either the Dutch Lynch syndrome registry (DLSR) between 1987 and 2016, and/or the cohort at the University Medical Center Groningen (UMCG) between 1993 and 2016 were included. Clinical data on age at diagnosis, mutation type, histological type, FIGO stage, treatment, follow-up and gynecological surveillance were collected.

Results. A total of 46/798 (6\%) women in the DLSR and 7/80 (9\%) in the UMCG cohort were identified as LS associated ovarian cancer patients. The median age at ovarian cancer diagnosis was 46.0 years (range 20-75 years). The most frequently reported histological type was endometrioid adenocarcinoma ( $40 \% ; n=$ 21 ) and serous carcinoma (36\%; $n=19)$. Most tumors ( $87 \% ; n=46)$ were detected at an early stage (FIGO I/ II). Forty-one of $53(77 \%)$ patients were diagnosed with ovarian cancer before LS was diagnosed. In the other 12/53 (23\%) women, ovarian cancer developed after starting annual gynecological surveillance for LS; three ovarian cancers were screen-detected in asymptomatic women. Overall survival was $83 \%$.

Conclusion. Ovarian cancer in women with LS has a wide age-range of onset, is usually diagnosed at an early stage with predominantly endometrioid type histology and a good overall survival. The early stage at diagnosis could not be attributed to annual gynecological surveillance.

(c) 2018 Published by Elsevier Inc.

\footnotetext{
* Corresponding author at: Department of Gynecologic Oncology, University of Groningen, University Medical Center Groningen, P.O. Box 30.001, 9700 RB Groningen, The Netherlands.

E-mail address: j.m.woolderink@umcg.nl (J.M. Woolderink).
}

\section{Introduction}

Hereditary predisposition accounts for approximately $5 \%$ of endometrial cancers and up to $24 \%$ of epithelial ovarian cancers [1,2]. LS is an autosomal dominant tumor syndrome, caused by a germline mutation in one of the DNA mismatch repair (MMR) genes, which, after a 
loss of function mutation of the normal allele, leads to microsatellite instability (MSI) and increased cancer risk. It accounts for most inherited endometrial cancers and a minority of inherited ovarian cancers, whereas a germline mutation in a BRCA1 or BRCA2 gene accounts for most inherited ovarian cancers [3-6]. In women with LS, endometrial cancer is after colon cancer the most common tumor type, $[7,8]$ with a cumulative lifetime risk of $15-60 \%$ and a mean age at diagnosis of $55-60$ years, (range $30-80$ years) depending on which gene is mutated [7,9-11]. The cumulative lifetime risk of ovarian cancer in LS varies between 6 and 12\% with a reported mean age at diagnosis of around 45 years [7,11-15]. Endometrial surveillance by transvaginal ultrasound and endometrial sampling can be effective in diagnosing endometrial cancer at a pre-invasive or early stage $[9,16,17]$. The value of surveillance for ovarian cancer in LS has never been established and is under debate $[9,14,18]$. Ovarian cancer surveillance has not been proven effective in the general population and among women with a BRCA1/2 gene mutation [19-24]. Most sporadic and BRCA-associated ovarian cancers are diagnosed at an advanced stage and interval ovarian cancers can present shortly after surveillance visits. In only a few surveillance studies a small number of women with LS are included, the information about clinical and histopathological characteristics of ovarian cancer in women with LS is therefore scattered and unclear [15,25-27].

The aim of this study was to analyze the clinical and histopathological characteristics of LS associated ovarian cancer and to investigate the role of surveillance in the early detection of these ovarian cancers.

\section{Materials and methods}

For this study, data of two prospective cohorts of ovarian cancer patients were used. The first cohort was derived from the Dutch Lynch Syndrome Registry (DLSR) between 1987 and 2016. The second cohort was from the Family Cancer Clinic at the University Medical Center Groningen (UMCG) between 1993 and 2016. The DLSR was started in 1987 and embedded in The Netherlands Foundation for the detection of Hereditary Tumors, which was established in 1985 [28]. Data managers of the Netherlands Foundation for the detection of Hereditary Tumors registry prospectively collect information on surveillance and cancer diagnosis in families with genetic cancer syndromes. All patients registered in the DLSR have given written informed consent before their medical information was collected in the DLSR.

The second cohort consists of all women with LS from the Family Cancer Clinic of the UMCG. All women gave written informed consent before their medical information was collected in the UMCG LS registry.

Protection of a patient's identity was guaranteed by assigning study specific unique patient numbers. The Medical Research Involving Human Subjects Act (Dutch: WMO) is not applicable to this study since it is a study using anonymized data from medical records. Therefore, the study was exempted from being approved by the Institutional Review Board.

\subsection{Inclusion criteria}

Women with LS associated ovarian cancer (i.e. proven carrier of a pathogenic mutation in either MLH1, MSH2, MSH6 or PMS2 or with a family history fulfilling the Amsterdam criteria) who developed ovarian cancer before or after the diagnosis of LS within the fore mentioned study period, were included in this study. There were no LS associated ovarian cancer patients who also carried a BRCA $1 / 2$ mutation.

\subsection{Data collection}

For all women with LS associated ovarian cancer in both cohorts, the following data was extracted: the age at diagnosis of ovarian cancer, type of gene mutation, histopathology report of the ovarian cancer (from the DLSR, from the UMCG or from the hospital in the Netherlands where the patient had been treated), primary treatment as well as adjuvant treatment (chemotherapy, radiotherapy, hormonal therapy), the occurrence of synchronous and metachronous cancer, the number and date of a recurrence and the disease specific survival. Pathology review has not been performed. Only patients who gave permission for registration in the DLSR cohort or the UMCG database were included.

Data about surveillance was extracted from the patient files; whether or not the woman was under annual surveillance for LS before ovarian cancer was diagnosed, whether the ovarian cancer was screendetected or an interval cancer and the presence and type of symptoms at time of ovarian cancer diagnosis. All women with LS who underwent gynecological surveillance prior to diagnosis of ovarian cancer underwent annual transvaginal ultrasound, and measurement of CA125. According to the Dutch guideline on hereditary colon cancer, (2008, revised in 2015), it was also advised to perform standard endometrial sampling during gynecological surveillance in women with LS [29].

If data about the histopathology of ovarian cancer or surveillance were not available in the DLSR, this data was obtained from the hospitals in the Netherlands in which the surveillance and/or the treatment of the ovarian cancer were performed. If a woman with LS was registered in both databases $(n=42)$, she was counted in the DLSR only and not counted twice.

\subsection{Data analysis}

In this study, the median age at diagnosis of ovarian cancer was described and also the mean age, to be able to compare these data with other studies, which mostly report the mean age at diagnosis. Differences (in stage, histological type, treatment, and outcome) between screen-detected ovarian cancers and ovarian cancers found by symptoms were studied. Statistical analysis was performed by chi-square testing or Mann-Whitney U testing, depending on the type of variables. Overall survival was defined as the interval from the date of ovarian cancer diagnosis to the date of dead of disease. The Kaplan-Meier method was used to create overall survival curves. The data analysis was performed with SPSS statistics version 20.

\section{Results}

The DLSR contained 798 female LS carriers. The mean age of this cohort was 58 years with a median age of 58 years (range 23-98 years), at time of study entry. In this registry 241 (30\%) women were carrier of a MLH1 gene mutation, 276 (35\%) of a MSH2, 237 (30\%) of a MSH6, 41 (5\%) had a PMS2 gene mutation and for three women, (who were included in the early days from families fulfilling the Amsterdam criteria) the type of mutation was not recorded. (Table 1) The cohort of the UMCG consists of 80 female LS carriers with a mean age of 49 years (range 28-75 years) and a median age of 48 years at ovarian cancer diagnosis. In 27 (36\%) women a MLH1 gene mutation was present, 18 (24\%) had a MSH2, 18 (24\%) a MSH6, 13 (17\%) a PMS2 mutation and for four women the type of mutation is not known. (Table 1) In total 878 female LS women were included in this study of which only patients with LS associated ovarian cancer are analyzed.

Forty-six of 798 women (6\%) of the DLSR had LS associated ovarian cancer and seven of 80 (9\%) of the UMCG cohort. (Table 2) The mean age at ovarian cancer diagnosis in these 53 patients was 46 years, with a median age of 46 years (range 20-75 years). Twenty-five percent of the women with LS associated ovarian cancer were diagnosed before the age of 40 . (Table 2 and Fig. 1) Of both cohorts $4,9 \%$ of all LS carriers had developed ovarian cancer by age 50 and $8.5 \%$ by age 70 . (Table 1 ) In $48 / 53$ women with LS associated ovarian cancer, the mutation status was known and consisted of 12 MLH1, 18 MSH2, 16 MSH6 and 2 PMS2 gene mutation carriers. (Table 2) In five cases LS was diagnosed based on family history fulfilling the Amsterdam criteria, however the type of mutation had not been noted. 
Table 1

Baseline characteristics of women with LS in the two cohorts $(n=878)$.

\begin{tabular}{|c|c|c|c|}
\hline & Women in the Dutch Lynch syndrome registry $(n=798)$ & Women in the UMCG registry $(n=80)$ & Both registries $(n=878)$ \\
\hline Age at study entry, mean (SD) in years ${ }^{a}$ & $58.0(14.1)$ & $49.4(10.7)$ & $57.2(13.9)^{\mathrm{b}}$ \\
\hline Age at study entry, median (range) in years ${ }^{\mathrm{a}}$ & $57.9(23-98)$ & $48.0(28-75)$ & $56.6(23-98)^{b}$ \\
\hline \multicolumn{4}{|c|}{ Gene mutation } \\
\hline MLH1 & $241(30 \%)$ & $27(36 \%)$ & $268(31 \%)$ \\
\hline MSH2 & $276(35 \%)$ & $18(24 \%)$ & $294(34 \%)$ \\
\hline MSH6 & $237(30 \%)$ & $18(24 \%)$ & $255(29 \%)$ \\
\hline PMS2 & $41(5 \%)$ & $13(17 \%)$ & $54(6 \%)$ \\
\hline Type unknown & 3 & 4 & 7 \\
\hline LS associated ovarian cancer in both cohorts & $46(6 \%)$ & $7(9 \%)$ & $53(6 \%)$ \\
\hline $\begin{array}{l}\text { \% diagnosed with ovarian cancer } \\
\text { by age } 50\end{array}$ & & & $(4.9 \%)$ \\
\hline by age 70 & & & $(8.5 \%)$ \\
\hline
\end{tabular}

a 1.1.2016 was taken as year of study entry.

b For fifteen patients this information was not available, as they were not alive at 1.1.2016.

The mean age of diagnosis of ovarian cancer was 46 years (median 45 years; range 39-53 years) in MLH1 gene mutation carriers, 41 years (median 40 years; range $20-58$ years) in $M S H 2$, 46 years (median 50 years; range 27-57 years) in MSH6 carriers and the two PMS2 carriers were respectively 44 and 47 years old. There was no significant difference between the MLH1, MSH2 and MSH6 gene mutation carriers and the age of diagnosis of ovarian cancer ( $p$ values $>0.05$ ). (Table 2 ).

Histological types and FIGO stages are shown in Table 2. The most frequent histopathological types were endometrioid ( $n=21 ; 40 \%$ ) and serous carcinoma ( $n=19 ; 36 \%)$. Of the latter, 13 patients were

Table 2

Clinical characteristics of patients with LS associated ovarian cancer $(n=53)$.

\begin{tabular}{|c|c|}
\hline Characteristics & $\mathrm{N}(\%)^{\mathrm{a}}$ \\
\hline Age at study entry, mean (SD) in years & $46.1(9.9)$ \\
\hline $\begin{array}{l}\text { Age at study entry, median (range) in } \\
\text { years }\end{array}$ & $46.0(20-75)$ \\
\hline \multicolumn{2}{|l|}{ Age at diagnosis (in years) } \\
\hline $20-29$ & $3(6 \%)$ \\
\hline $30-39$ & $10(19 \%)$ \\
\hline $40-49$ & $20(38 \%)$ \\
\hline $50-59$ & $16(30 \%)$ \\
\hline $60-59$ & $3(6 \%)$ \\
\hline $70-79$ & $1(2 \%)$ \\
\hline \multicolumn{2}{|l|}{ Gene mutation } \\
\hline MLH1 & $12(25 \%)$ \\
\hline MSH2 & $18(38 \%)$ \\
\hline MSH6 & $16(33 \%)$ \\
\hline PMS2 & $2(4 \%)$ \\
\hline Type unknown & 5 \\
\hline \multicolumn{2}{|c|}{ Age at diagnosis and gene mutation, mean (median \& range) in years; $p$ value } \\
\hline MLH1 & 46 (45 \& 39-53) MLH1 vs MSH2: 0.08 \\
\hline MSH2 & $\begin{array}{l}41 \text { (40 \& 20-58) MSH2 vs MSH6: } \\
0.78\end{array}$ \\
\hline MSH6 & 46 (50 \& 27-57) MSH6 vs MLH1: 0.12 \\
\hline PMS2 & 44 and 47 \\
\hline \multicolumn{2}{|l|}{ Histopathology } \\
\hline Endometrioid carcinoma & $21(40 \%)$ \\
\hline High grade serous carcinoma & $13(25 \%)$ \\
\hline Low grade serous carcinoma & $6(11 \%)$ \\
\hline Clear cell carcinoma & $3(6 \%)$ \\
\hline Mucinous carcinoma & $1(2 \%)$ \\
\hline Other epithelial & $3(6 \%)$ \\
\hline Non epithelial & $2(4 \%)$ \\
\hline Borderline tumor & $3(6 \%)$ \\
\hline Unknown & 1 \\
\hline \multicolumn{2}{|l|}{ FIGO stage } \\
\hline Stage I & 38 (72\%) \\
\hline Stage II & $8(15 \%)$ \\
\hline Stage III & $7(13 \%)$ \\
\hline Stage IV & - \\
\hline
\end{tabular}

\footnotetext{
a Unless specified otherwise.
}

diagnosed with high grade serous carcinoma, (five FIGO stage I, three FIGO stage II and four FIGO stage III carcinoma) and six with low grade serous carcinoma (all FIGO stage I carcinoma). The majority of patients ( $n=46 ; 87 \%$ ) were diagnosed at an early stage (FIGO stage I/II). Seven patients were diagnosed with advantaged stage (FIGO stage III) ovarian cancer.

Table 3 shows the clinical course of all patients with LS associated ovarian cancer. Regarding the surveillance after diagnosis of ovarian cancer: all LS associated ovarian cancer patients underwent oncological follow up at least twice a year. The mean follow-up period after ovarian cancer diagnosis was 136 months (median 114; range 1-517 months). Fifty of 53 ovarian cancer patients were diagnosed through symptoms, mostly abnormal vaginal bleeding $(n=15 ; 30 \%)$ and/or abdominal pain $(\mathrm{n}=15 ; 30 \%)$. Other reported symptoms were abdominal distension $(n=9 ; 18 \%)$ and pelvic organ prolapse $(n=1 ; 2 \%)$. For ten $(20 \%)$ patients the presenting type of symptoms was unspecified. (Table 3).

For 48 (91\%) of these LS associated ovarian cancer patients, ovarian cancer was the first cancer in their life. In 17 of these patients ovarian cancer was diagnosed synchronously with a (pre) malignancy of the endometrium or colon (Table 3). Seventeen (32\%) women developed a metachronous second cancer after the diagnosis of ovarian cancer, mostly $(n=8)$ colon cancer. Survival data are available for 46 patients. Nine (19\%) patients developed recurrent ovarian cancer with a mean time to recurrence of 49 months (median 38; range 3-120 months) and eight women with LS associated ovarian cancer (17\%) died of the disease (Table 3). The overall survival of LS associated ovarian cancer in this study was $83 \%$.

Only 12 of the 53 women were identified as being a LS carrier before ovarian cancer diagnosis and underwent annual gynecological ovarian cancer surveillance consisting of transvaginal ultrasound, endometrial sampling and measurement of CA125. (Tables 4 and 5) During a total of 37 surveillance years, one interval ovarian cancer was diagnosed in a 41-year-old woman who presented with abdominal pain five months after a negative surveillance (FIGO stage IC). Of the other 11 patients with LS associated ovarian cancer, three were diagnosed during surveillance (screen-detected) because of an abdominal mass at TVU (two FIGO stage IA, one stage IC). The other eight women reported abnormal vaginal bleeding during a surveillance visit. All 12 ovarian cancers in patients who underwent annual surveillance were detected at an early stage; 10 FIGO stage I and two FIGO stage II (Tables 4 and 5). There were no significant differences in FIGO stage at diagnosis between the patients who underwent surveillance and those who did not ( $p=$ 0.31 ). The other 41 women developed ovarian cancer before the diagnosis of LS. (Table 4).

\section{Discussion}

This study included 53 LS associated ovarian cancer patients which is one of the largest reported cohort. The mean and median age of the 


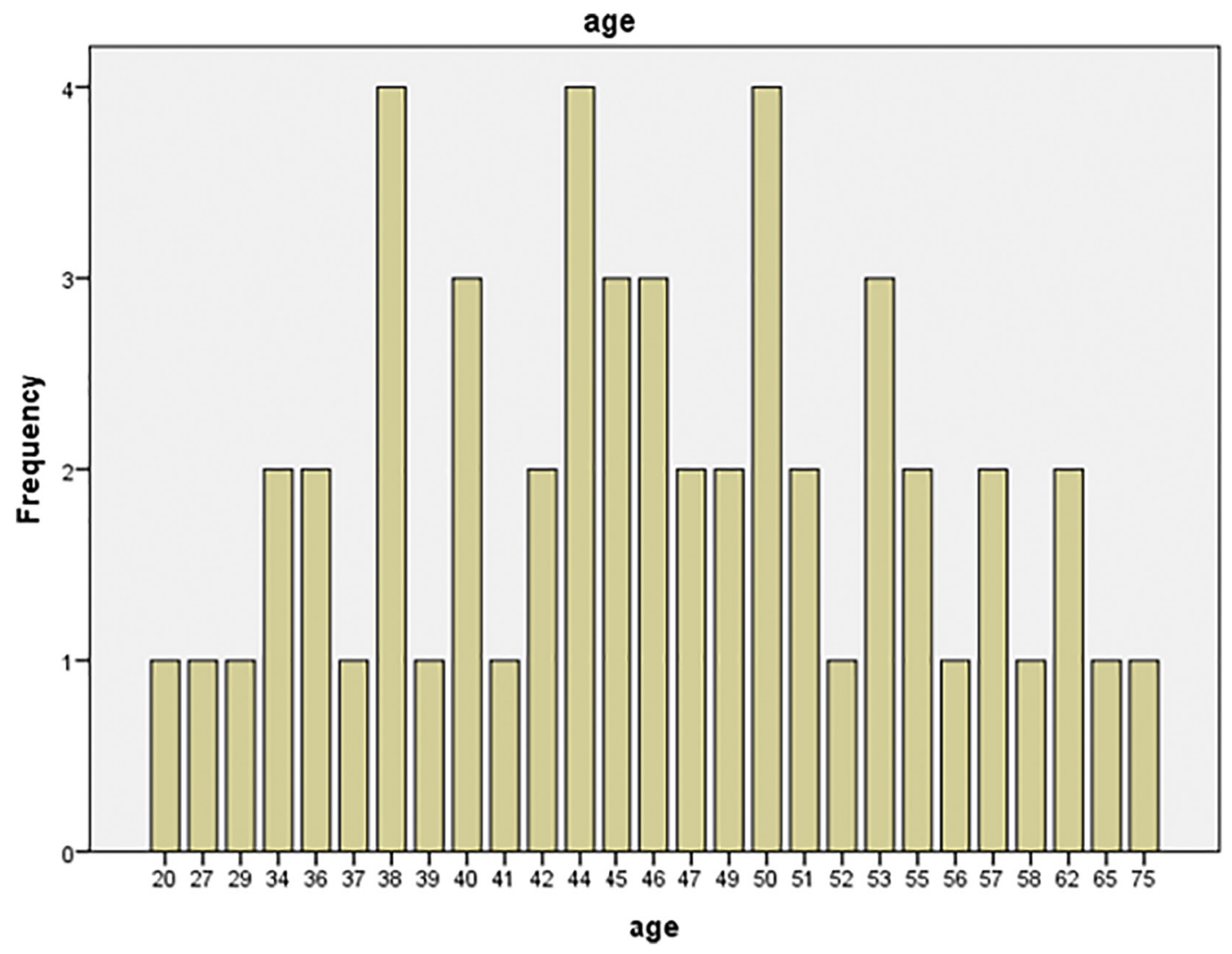

Fig. 1. Age at ovarian cancer diagnosis $(n=53)$ in women with LS-associated ovarian cancer.

ovarian cancer diagnosis was 46 years, with a wide age range of 20-75 years. A total of $25 \%$ of the women were under 40 years of age at diagnosis of LS associated ovarian cancer. Histopathological presentation was most often an endometrioid or serous type and most ovarian cancers were diagnosed at an early stage (87\% FIGO stage I/II) with a relatively good five year survival (78\%). Data about surveillance before ovarian cancer diagnosis was available for $12 / 53$ patients and Three of 12 were screen-detected ovarian cancers, all FIGO stage I. Six of 12 screened patients were diagnosed with a (pre)malignancy of the endometrial tissue for which they received surgery which led to ovarian cancer diagnosis.

In this study, the mean age of LS associated ovarian cancer diagnosis was 46 years with a wide age range. This is comparable with the age at diagnosis in 551 ovarian cancer patients with LS described in a recent review of the literature, with a mean age of 45.3 years (range 19-92 years), and with a recently published cohort study of 53 ovarian cancers in LS with a mean age of 51 years (range 24-70 years) [14,15]. As a hereditary cause of ovarian cancer is more often suspected in young women with ovarian cancer, an over-presentation of testing young women for LS (and BRCA mutation) might have occurred in this study, which is probably also the case in other published studies [14]. This may have introduced a bias in age at diagnosis of those LS associated ovarian cancers in these studies. LS associated ovarian cancer seems to occur approximately 15-20 years earlier than sporadic and BRCA2 gene mutation related ovarian cancer $[23,25,26,30-32]$ and $5-10$ years earlier than in women with a BRCA1 gene mutation $[20,32,33]$.

In none of the studies, nor in our study, the age at diagnosis of LS associated ovarian cancer was significantly different between the mutation types [15,34].

For 48 (91\%) patients, LS associated ovarian cancer was the first cancer in their life and for 17 of these another malignancy was diagnosis at the same time (synchronously). This high percentage is explained by the fact that LS associated ovarian cancer was the inclusion criterion and the starting point of this study.

The distribution of histological types of ovarian cancer in women with LS in this study is different from sporadic cases. In this study $65 \%$ of the ovarian cancers were of non-serous type. This has also been described in smaller studies in women with LS associated ovarian cancer and in a recent systematic review about ovarian cancer in women with LS $[14,26,35]$. In sporadic and BRCA1/2 cases the majority of ovarian cancers are of the high-grade serous type $[20,23,30]$.

Most ovarian cancers (87\%) in this study were diagnosed at an early stage (FIGO I/II). These ovarian cancers have a five-year survival rate of above $80 \%$ as published before in smaller series $[14,27,30]$. This contrasts with sporadic and BRCA1-2 gene related cases in which $60-70 \%$ of ovarian cancers are diagnosed at FIGO stage III-IV, with a 10 -year survival rate of $<40 \%[20,32,36]$. There was no significant difference in FIGO stage at diagnosis between the patients who underwent surveillance $(n=12)$ and those who did not $(n=41)$.

As only 3/12 cases were truly screen-detected (diagnosed during screening in asymptomatic women), the early stage of ovarian cancer in LS in this series and the good overall survival are most probably not related to surveillance but to the biological behavior of these ovarian cancers. To our knowledge, six other studies described the results of gynecological surveillance in women with LS $(n=674)$. Of a total of 674 LS carriers under surveillance, 22 (3\%) developed ovarian cancer, mostly detected at an early stage with a good overall survival. Only $7 / 22$ (32\%) of these ovarian cancers were detected during surveillance, the other 15 were interval cancers $[9,14,16,18,37-39]$. Of the 12 women who underwent annual surveillance in our study, eight women presented with symptoms of abnormal uterine bleeding. In six of these women 
Table 3

Clinical course of LS associated ovarian cancers; overall and stratified by FIGO stage ( $n$ $=53$ ).

\begin{tabular}{|c|c|c|c|}
\hline \multirow[t]{2}{*}{ Characteristics } & \multirow{2}{*}{$\begin{array}{l}\mathrm{N}(\%)^{\mathrm{a}} \\
\text { Overall } \\
N=53\end{array}$} & \multirow{2}{*}{$\begin{array}{l}\mathrm{N}(\%)^{\mathrm{b}} \\
\text { FIGO } \\
\text { stage } \\
\mathrm{I} / \mathrm{II} N= \\
46\end{array}$} & \multirow{2}{*}{$\begin{array}{l}\mathrm{N}(\%)^{\mathrm{c}} \\
\text { FIGO } \\
\text { stage } \\
\text { III/IV } N \\
=7\end{array}$} \\
\hline & & & \\
\hline Follow-up, mean (SD) in months & $\begin{array}{l}136 \\
(121)\end{array}$ & $\begin{array}{l}151 \\
(123)\end{array}$ & $43(40)$ \\
\hline Follow-up, median (range) in months & $\begin{array}{l}114 \\
(1-517)\end{array}$ & $\begin{array}{l}132 \\
(5-517)\end{array}$ & $\begin{array}{l}42 \\
(4-122)\end{array}$ \\
\hline \multicolumn{4}{|l|}{ Under surveillance } \\
\hline No & $41(77 \%)$ & $\begin{array}{l}34 \\
(74 \%)\end{array}$ & $\begin{array}{l}7 \\
(100 \%)\end{array}$ \\
\hline Diagnosed with symptoms & $\begin{array}{l}41 \\
(100 \%)\end{array}$ & $\begin{array}{l}34 \\
(100 \%)\end{array}$ & $\begin{array}{l}7 \\
(100 \%)\end{array}$ \\
\hline Yes & $12(23 \%)$ & $\begin{array}{l}12 \\
(26 \%)\end{array}$ & - \\
\hline Diagnosed with symptoms & $9(75 \%)$ & $9(75 \%)$ & - \\
\hline Symptoms during diagnosis & $50(93 \%)$ & $\begin{array}{l}43 \\
(93 \%)\end{array}$ & $\begin{array}{l}7 \\
(100 \%)\end{array}$ \\
\hline Blood loss & $15(30 \%)$ & $\begin{array}{l}14 \\
(33 \%)\end{array}$ & $1(14 \%)$ \\
\hline Abdominal pain & $15(30 \%)$ & $\begin{array}{l}14 \\
(33 \%)\end{array}$ & $1(14 \%)$ \\
\hline Abdominal distension & $9(18 \%)$ & $5(12 \%)$ & $4(57 \%)$ \\
\hline Pelvic organ prolapse & $1(2 \%)$ & $1(2 \%)$ & - \\
\hline Unspecified & $10(20 \%)$ & $9(21 \%)$ & $1(14 \%)$ \\
\hline \multicolumn{4}{|l|}{ First cancer } \\
\hline Ovarian cancer only & $31(58 \%)$ & $\begin{array}{l}26 \\
(57 \%)\end{array}$ & $5(71 \%)$ \\
\hline $\begin{array}{l}\text { Ovarian cancer and synchronous endometrial } \\
\text { cancer }\end{array}$ & $14(26 \%)$ & $\begin{array}{l}13 \\
(28 \%)\end{array}$ & $1(14 \%)$ \\
\hline $\begin{array}{l}\text { Ovarian cancer and synchronous complex } \\
\text { atypical hyperplasia }\end{array}$ & $2(4 \%)$ & $2(4 \%)$ & - \\
\hline Ovarian cancer and synchronous colon cancer & $1(2 \%)$ & - & $1(14 \%)$ \\
\hline Colon cancer & $3(6 \%)$ & $3(7 \%)$ & - \\
\hline Endometrial cancer & $1(2 \%)$ & $1(2 \%)$ & - \\
\hline Breast cancer & $1(2 \%)$ & $1(2 \%)$ & - \\
\hline \multicolumn{4}{|l|}{$\begin{array}{l}\text { Metachronous cancer during follow up after LS } \\
\text { associated ovarian cancer }\end{array}$} \\
\hline No & $36(68 \%)$ & $\begin{array}{l}31 \\
(67 \%)\end{array}$ & $5(86 \%)$ \\
\hline Yes & $17(32 \%)$ & $\begin{array}{l}15 \\
(33 \%)\end{array}$ & $1(14 \%)$ \\
\hline Colon cancer & $8(47 \%)$ & $8(53 \%)$ & - \\
\hline And urothelial cell cancer ${ }^{\mathrm{b}}$ & $1(6 \%)$ & $1(7 \%)$ & - \\
\hline And sarcoma ${ }^{\mathrm{b}}$ & $1(6 \%)$ & - & $1(50 \%)$ \\
\hline And pancreas cancer & $1(6 \%)$ & $1(7 \%)$ & - \\
\hline Breast cancer & $3(18 \%)$ & $3(20 \%)$ & - \\
\hline Appendicular cancer & $1(6 \%)$ & $1(7 \%)$ & - \\
\hline Mediastinal cancer & $1(6 \%)$ & $1(7 \%)$ & - \\
\hline Endometrial cancer & $1(6 \%)$ & - & $1(50 \%)$ \\
\hline \multicolumn{4}{|l|}{ Recurrence of ovarian cancer $(n=51)^{c}$} \\
\hline No & $42(82 \%)$ & $\begin{array}{l}37 \\
(84 \%)\end{array}$ & $5(71 \%)$ \\
\hline Yes & $9(18 \%)$ & $7(16 \%)$ & $2(29 \%)$ \\
\hline Time to recurrence, mean (SD) in months & $49(42)$ & $56(48)$ & $23(2)$ \\
\hline Time to recurrence, median (range) & $\begin{array}{l}38 \\
(3-120)\end{array}$ & $\begin{array}{l}40 \\
(3-120)\end{array}$ & $\begin{array}{l}23 \\
(21-24)\end{array}$ \\
\hline \multicolumn{4}{|l|}{ Died of ovarian cancer $(n=46)^{\mathrm{d}}$} \\
\hline No & $38(83 \%)$ & $\begin{array}{l}35 \\
(90 \%)\end{array}$ & $3(43 \%)$ \\
\hline Yes & $8(17 \%)$ & $4(10 \%)$ & $4(57 \%)$ \\
\hline
\end{tabular}

a Unless specified otherwise.

b This was metachronous cancer diagnosed after colon cancer.

c For two cases with FIGO stage I/II, this was unknown.

d For seven cases with FIGO stage I/II, this was unknown.

ovarian cancer was detected synchronously with an endometrial (pre) malignancy and in the other two no endometrial abnormalities were found. The high level (10-25\%) of synchronous cancers, (mostly endometrial cancer), in women with LS associated ovarian cancer has been reported earlier $[15,26]$. It might be difficult for the pathologist to discern
Table 4

Characteristics of LS associated ovarian cancer of women who underwent annual surveillance $(n=12)$ and those who did not $(n=41)$.

\begin{tabular}{|c|c|c|}
\hline \multirow[t]{2}{*}{ Characteristics } & \multirow{2}{*}{$\begin{array}{l}\mathrm{N}(\%)^{\mathrm{a}} \\
\text { Surveillance } \\
\text { group } n \\
=12(23 \%)\end{array}$} & \multirow{2}{*}{$\begin{array}{l}\mathrm{N}(\%) \\
\text { Non-surveillance } \\
\text { group } \\
n=41(77 \%)\end{array}$} \\
\hline & & \\
\hline Age at diagnosis, mean (SD) in years & $48.0(6.6)$ & $45.6(10.6)$ \\
\hline Age at diagnosis, median (range) in years & $46.5(41-65)$ & $45.0(20-75)$ \\
\hline \multicolumn{3}{|l|}{ Histopathology } \\
\hline Endometrioid carcinoma & $8(67 \%)$ & $13(33 \%)$ \\
\hline High grade serous carcinoma & $2(17 \%)$ & $11(28 \%)$ \\
\hline Low grade serous carcinoma & - & $6(15 \%)$ \\
\hline Clear cell carcinoma & $1(8 \%)$ & $3(7 \%)$ \\
\hline Mucinous carcinoma & - & $1(2 \%)$ \\
\hline Other epithelial tumor & $1(8 \%)$ & $1(2 \%)$ \\
\hline Non epithelial tumor & - & $2(5 \%)$ \\
\hline Borderline tumor & - & $3(7 \%)$ \\
\hline Unknown & - & 1 \\
\hline \multicolumn{3}{|l|}{ FIGO stage ${ }^{\mathrm{b}}$} \\
\hline Stage I & $10(83 \%)$ & $28(68 \%)$ \\
\hline Stage II & $2(17 \%)$ & $6(15 \%)$ \\
\hline Stage III & - & $7(17 \%)$ \\
\hline Stage IV & - & - \\
\hline \multicolumn{3}{|l|}{ Ovarian cancer and synchronous } \\
\hline Endometrial cancer & $4(33 \%)$ & $10(24 \%)$ \\
\hline $\begin{array}{l}\text { Complex atypical hyperplasia } \\
\text { endometrial tissue }\end{array}$ & $2(17 \%)$ & - \\
\hline Colon cancer & - & $1(2 \%)$ \\
\hline \multicolumn{3}{|l|}{ Died of ovarian cancer $(n=46)^{c}$} \\
\hline No & $12(100 \%)$ & $26(76 \%)$ \\
\hline Yes & $0-$ & $8(24 \%)$ \\
\hline
\end{tabular}

endometrioid ovarian cancer from an ovarian metastasis of endometrioid endometrial cancer, although endometrial premalignancies will not give ovarian metastases and this is also very scarce in early stage endometrial cancers [15,25].

The early diagnosis of LS associated ovarian cancer may in part be explained by symptoms such as vaginal bleeding, resulting in endometrial (pre)cancer diagnosis and treatment and discovery of an occult, synchronous ovarian cancer during surgery. The latter was the case in half of the screened women. However this phenomenon could not be studied in the women who were diagnosed with ovarian cancer before LS was diagnosed.

Another explanation for the favorable outcome might be a different biological characteristics of these tumors as histopathology differs from sporadic and BRCA1/2 cases. More information on the molecular biology of these tumors is needed to explain the early stage at diagnosis and the relative good prognosis of LS associated ovarian cancer when compared to sporadic and $B R C A$ associated cases.

The results of this study have a clinical utility in case of counseling about (dis)advantages and timing of preventive surgery in women with LS. Although preventive surgery is very effective in preventing gynecological cancers in LS, the wide age range, the very young age at diagnosis in part of the patients with LS associated ovarian cancer, together with the development of mostly early stage cancers with a good prognosis make it difficult to formulate an advise for timing the optimal age for preventive surgery in these women [40]. Also premature menopause and its side effects should be taken into account and individualization of preventive strategies is preferable.

The strength of this study is the longitudinal database, the proven mutation status of almost all ovarian cancer patients and the relatively large cohort of 53 LS associated ovarian cancers. A limitation of this study is the long period of time leading to some missing data and the 
Table 5

Characteristics of LS associated ovarian cancer in women who underwent annual surveillance $(n=12)$

\begin{tabular}{|c|c|c|c|c|c|c|c|c|c|c|}
\hline No & $\begin{array}{l}\text { Age at } \\
\text { ovarian } \\
\text { cancer } \\
\text { diagnosis }\end{array}$ & $\begin{array}{l}\text { Start } \\
\text { survei-llance }\end{array}$ & $\begin{array}{l}\text { Year } \\
\text { ovarian } \\
\text { cancer }\end{array}$ & Symptoms & $\begin{array}{l}\text { Screening } \\
\text { endometri } \\
\text { mm thickn } \\
\text { histopatho } \\
\text { endometri }\end{array}$ & $\begin{array}{l}\text { sults ovaries \& } \\
\text { m (by TVU\# in } \\
\text { ss) and } \\
\text { gy by } \\
\text { sampling }\end{array}$ & $\begin{array}{l}\text { CA } \\
125 \\
\text { Level } \\
(\mathrm{kU} / \mathrm{l})\end{array}$ & $\begin{array}{l}\text { FIGO\#\# stage \& } \\
\text { histopathology } \\
\text { ovaries }\end{array}$ & $\begin{array}{l}\text { FIGO stage \& } \\
\text { histopa-thology } \\
\text { endome-trium }\end{array}$ & $\begin{array}{l}\text { Dead } \\
\text { of } \\
\text { disease }\end{array}$ \\
\hline 1 & 55 & 2001 & 2005 & Postmenopausal bleeding & $\begin{array}{l}\text { Adnexal } \\
\text { mass }\end{array}$ & $\begin{array}{l}6 \mathrm{~mm}, \\
\text { SamplingCAH }^{\mathrm{a}}\end{array}$ & 213 & $\begin{array}{l}\text { IB, } \\
\text { Endome- } \\
\text { trioid }\end{array}$ & $\overline{C A H}^{\mathrm{a}}$ & no \\
\hline 2 & 46 & 1999 & 2001 & Irregular bleeding & $\begin{array}{l}\text { Normal } \\
\text { ovaries }\end{array}$ & $\begin{array}{l}10 \mathrm{~mm} \text {, } \\
\text { SamplingEA } \\
\text { grade } 1\end{array}$ & 418 & $\begin{array}{l}\text { IA, } \\
\text { Endome- } \\
\text { trioid }\end{array}$ & $\begin{array}{l}\text { IB, } \\
\text { Endometrioid }\end{array}$ & no \\
\hline 3 & 51 & 2005 & 2009 & Postmenopausal bleeding & $\begin{array}{l}\text { Normal } \\
\text { ovaries }\end{array}$ & $\begin{array}{l}7 \mathrm{~mm} \text {, } \\
\text { Sampling } \\
\mathrm{EA}^{\mathrm{b}} \text { grade } 1\end{array}$ & $\begin{array}{l}\text { Un } \\
\text { known }\end{array}$ & $\begin{array}{l}\text { IIA, } \\
\text { Endome- } \\
\text { trioid }\end{array}$ & IA, Endometrioid & no \\
\hline 4 & 66 & 1996 & 1998 & Postmenopausal bleeding & $\begin{array}{l}\text { Adnexal } \\
\text { mass }\end{array}$ & $\begin{array}{l}\text { Unknown } \\
\text { Samplingnormal }\end{array}$ & 66 & $\begin{array}{l}\text { IIB, } \\
\text { High grade } \\
\text { serous }\end{array}$ & $\begin{array}{l}\text { - } \\
\text { Uterine metastasis of } \\
\text { ovarian cancer }\end{array}$ & no \\
\hline 5 & 45 & 2013 & 2014 & Irregular bleeding & $\begin{array}{l}\text { Normal } \\
\text { ovaries }\end{array}$ & $\begin{array}{l}15 \mathrm{~mm} \text {, } \\
\text { SamplingEA } \\
\text { grade } 1\end{array}$ & 38 & IA, Endome-trioid & IA, Endometrioid & no \\
\hline 6 & 47 & 2011 & 2013 & None & $\begin{array}{l}\text { Adnexal } \\
\text { mass }\end{array}$ & $\begin{array}{l}13 \mathrm{~mm} \text {, } \\
\text { Samplingnormal }\end{array}$ & 34 & $\begin{array}{l}\text { IA } \\
\text { Intestinal type } \\
\text { adenocarci- } \\
\text { noma }\end{array}$ & - & no \\
\hline 7 & 47 & 2013 & 2013 & Irregular bleeding & $\begin{array}{l}\text { Normal } \\
\text { ovaries }\end{array}$ & $\begin{array}{l}4 \mathrm{~mm}, \\
\text { SamplingCAH }\end{array}$ & 8 & IA, Endome-trioid & $\begin{array}{l}-, \\
\text { Complex atypical } \\
\text { hyperplasia }\end{array}$ & no \\
\hline 8 & 44 & 2009 & 2011 & Irregular bleeding & $\begin{array}{l}\text { Normal } \\
\text { ovaries }\end{array}$ & $\begin{array}{l}\text { Unknown } \\
\text { SamplingEA } \\
\text { grade } 1\end{array}$ & 141 & $\begin{array}{l}\text { IA, } \\
\text { Endome-trioid }\end{array}$ & $\begin{array}{l}\text { IIA, } \\
\text { Endometrioid }\end{array}$ & no \\
\hline 9 & 49 & 2005 & 2014 & None & $\begin{array}{l}\text { Adnexal } \\
\text { mass }\end{array}$ & $\begin{array}{l}8 \mathrm{~mm} \text {, } \\
\text { Sampling } \\
\text { normal }\end{array}$ & 39 & $\begin{array}{l}\text { IC, } \\
\text { Endome-trioid }\end{array}$ & - & no \\
\hline 10 & 44 & 1999 & 2000 & Menorraghia & $\begin{array}{l}\text { Adnexal } \\
\text { mass }\end{array}$ & $\begin{array}{l}9 \mathrm{~mm}, \\
\text { Samplingnormal }\end{array}$ & $\begin{array}{l}\text { Un } \\
\text { known }\end{array}$ & $\begin{array}{l}\text { IC, } \\
\text { Clearcell }\end{array}$ & - & no \\
\hline 11 & 41 & 2012 & 2015 & $\begin{array}{l}\text { Abdominal pain, } 5 \text { months, after } \\
\text { negative surveillance } \\
\text { Interval } \mathbf{O C}\end{array}$ & $\begin{array}{l}\text { Adnexal } \\
\text { mass and } \\
\text { ascites }\end{array}$ & $\begin{array}{l}7 \mathrm{~mm} \text {, } \\
\text { Samplingnormal }\end{array}$ & 25 & $\begin{array}{l}\text { IC, } \\
\text { High grade } \\
\text { serous }\end{array}$ & - & no \\
\hline 12 & 42 & 1999 & 2005 & None & $\begin{array}{l}\text { Adnexal } \\
\text { mass }\end{array}$ & $\begin{array}{l}4 \mathrm{~mm} \text {, } \\
\text { Samplingnormal }\end{array}$ & 61 & $\begin{array}{l}\text { IA, } \\
\text { Endome-trioid }\end{array}$ & - & no \\
\hline
\end{tabular}

The significance of bold represents the women in which ovarian cancer was found by surveillance and one with an interval carcinoma.

\# TVU: transvaginal ultrasonography.

\#\# FIGO 1991.

a $\mathrm{CAH}$ : complex atypical hyperplasia.

b EA: endometrioid adenocarcinoma.

small number of LS carriers who underwent annual surveillance before ovarian cancer was diagnosed. Another limitation is that no revision of the pathology reports was performed. In five cases in this study, in which women developed ovarian cancer many years ago when DNA analysis or mismatch repair (MMR) deficiency was not available, the diagnosis of LS was based on the Amsterdam criteria. As in these cases no DNA analysis was performed, it cannot be ruled out that some of these five are sporadic ovarian cancer cases. However, as in these women $(n=5)$ the families fulfilled the Amsterdam criteria for LS the chance that they are not a LS associated ovarian cancers is limited. Another limitation of this study design is that we were not able to estimate the penetrance of the several LS-related mutations, as all 53 patients with ovarian cancer were selected because they had LS-associated ovarian cancer. Not the LS carrier ship but the LS-associated ovarian cancer was the starting point of this study. Therefore this study design is not appropriate to estimate the cumulative risk of ovarian cancer in LS carriers.

In conclusion, ovarian cancer in women with LS may develop at a young age, with a wide age-range (20-75 years) of onset, a mean and median age at diagnosis of 46 years and is most often diagnosed at an early stage, not attributable to surveillance. LS associated ovarian cancer often has an endometrioid or serous histology with a relatively good overall survival.

Conflict of interest statement

All authors declare that there are no conflicts of interest.

\section{References}

[1] A. Aysal, A. Karnezis, I. Medhi, J.P. Grenert, C.J. Zaloudek, J.T. Rabban, Ovarian endometrioid adenocarcinoma: incidence and clinical significance of the morphologic and immunohistochemical markers of mismatch repair protein defects and tumor microsatellite instability, Am. J. Surg. Pathol. 36 (2012) 163-172.

[2] T. Walsh, S. Casadei, M.K. Lee, C.C. Pennil, A.S. Nord, A.M. Thornton, et al., Mutations in 12 genes for inherited ovarian, fallopian tube, and peritoneal carcinoma identified by massively parallel sequencing, Proc. Natl. Acad. Sci. U. S. A. 108 (44) (2011) 18032-18037.

[3] S.C. Rubin, M.A. Blackwood, C. Bandera, K. Behbakht, I. Benjamin, T.R. Rebbeck, J. Boyd, BRCA1, BRCA2, and hereditary nonpolyposis colorectal cancer gene mutations in an unselected ovarian cancer population: relationship to family history and implications for genetic testing, Am. J. Obstet. Gynecol. 178 (1998) 670-677.

[4] T. Pal, J. Permuth-Wey, J.A. Betts, J.P. Krischer, J. Fiorica, H. Arango, et al., BRCA1 and $B R C A 2$ mutations account for a large proportion of ovarian carcinoma cases, Cancer 104 (2005) 2807-2816. 
[5] M.D. Walsh, M.C. Cummings, D.D. Buchanan, W.M. Dambacher, S. Arnold, D. McKeone, et al., Molecular, pathologic, and clinical features of early-onset endometrial cancer: identifying presumptive Lynch syndrome patients, Clin. Cancer Res. 14 (2008) 1692-1700.

[6] H.T. Lynch, M.J. Casey, C.L. Snyder, C. Bewtra, J.F. Lynch, M. Butts, et al., Hereditary ovarian carcinoma: heterogenity, molecular genetics, pathology and management, Mol. Oncol. 3 (2009) 97-137.

[7] M. Aarnio, R. Sankila, E. Pukkala, R. Salovaara, L.A. Aaltonen, A. de la Chapelle, et al. Cancer risk in mutation carriers of DNA-mismatch-repair genes, Int. J. Cancer 81 (1999) 214-218.

[8] E. Barrow, L. Robinson, W. Alduaij, A. Shenton, T. Clancy, F. Lalloo, et al., Cumulative lifetime incidence of extracolonic cancers in Lynch syndrome: a report of $121 \mathrm{fam}-$ ilies with proven mutations, Clin. Genet. 75 (2009) 141-149.

[9] L. Renkonen-Sinisalo, R. Butzow, A. Leminen, P. Lehtovirta, J.P. Mecklin, H.J. Jarvinen, Surveillance for endometrial cancer in hereditary nonpolyposis colorectal cancer syndrome, Int. J. Cancer 120 (4) (2006) 821.

[10] L. Senter, M. Clendenning, K. Sotamaa, H. Hampel, J. Green, J.D. Potter, et al., The clinical phenotype of Lynch syndrome due to germ-line PMS2 mutations, Gastroenterology 135 (2008) 419-428.

[11] R. Moldovan, S. Keating, T. Clancy, The impact of risk-reducing gynaecological surgery in premenopausal women at high risk of endometrial and ovarian cancer due to lynch syndrome, Familial Cancer 14 (2015) 51-60.

[12] H.F. Vasen, A. Stormorken, F.H. Menko, F.M. Nagengast, J.H. Kleibeuker, G. Griffioen, et al., MSH2 mutation carriers are at higher risk of cancer than MLH1 mutation carriers: a study of hereditary nonpolyposis colorectal cancer families, J. Clin. Oncol. 19 (2001) 4074-4080.

[13] P. Watson, H.F. Vasen, J.P. Mecklin, I. Bernstein, M. Aarnio, H.J. Järvinen, et al., The risk of extra-colonic, extra-endometrial cancer in the lynch syndrome, Int. J. Cancer 123 (2008) 444-449.

[14] J.M. Helder-Woolderink, E.A. Blok, H.F.A. Vasen, H. Hollema, M.J. Mourits, G.H. De Bock, Ovarian cancer in Lynch syndrome; a systematic review, Eur. J. Cancer 55 (2016) 65-73.

[15] N.A.J. Ryan, D.G. Evans, K. Green, E.J. Crosbie, Pathological features and clinical behaviour of lynch syndrome-associated ovarian cancer, Gynecol. Oncol. 144 (3) (2017) 491-495.

[16] L.H.M. Gerritzen, N. Hoogerbrugge, A.L. Oei, F.M. Nagengast, M.A. Van Ham, L.F. Massuger, et al., Improvement of endometrial biopsy over transvaginal ultrasound alone for endometrial surveillance in women with Lynch syndrome, Familial Cancer 8 (2009) 391-397.

[17] J.M. Helder-Woolderink, G.H. De Bock, R.H. Sijmons, H. Hollema, M.J. Mourits, The additional value of endometrial sampling in the early detection of endometrial cancer in women with Lynch syndrome, Gynecol. Oncol. 131 (2013) 304-308.

[18] S. Stuckless, J. Green, L. Dawson, B. Barrett, M.O. Woods, E. Dicks, et al., Impact of gynecological screening in Lynch syndrome carriers with an MSH2 mutation, Clin. Genet. 83 (2013) 359-364

[19] I.J. Jacobs, S.J. Skates, N. MacDonald, U. Menon, A.N. Rosenthal, A.P. Davies, et al, Screening for ovarian cancer: a pilot randomised controlled trial, Lancet 353 (1999) 1207-1210.

[20] B.B. Hermsen, R.I. Olivier, R.H. Verheijen, M. van Beurden, J.A. de Hullu, L.F. Massuger, et al., No efficacy of annual gynaecological screening in BRCA1/2 mutation carriers; an observational follow-up study, Br. J. Cancer 96 (2007) 1335-1342.

[21] U. Menon, A. Gentry-Maharaj, R. Hallett, A. Ryan, M. Burnell, A. Sharma, et al., Sensitivity and specificity of multimodal and ultrasound screening for ovarian cancer, and stage distribution of detected cancers: results of the prevalence screen of the UK Collaborative Trial of Ovarian Cancer Screening (UKCTOCS), Lancet Oncol. 10 (2009) 327-340.
[22] N.M. Velde van der, M.J. Mourits, H.J. Arts, J. de Vries, B.K. Leegte, G. Dijkhuis, et al, Time to stop ovarian cancer screening in BRCA1/2 mutation carriers? Int. J. Cancer 124 (2009) 919-923.

[23] S.S. Buys, E. Partridge, A. Black, C.C. Johnson, L. Lamerato, C. Isaacs, et al., Effect of screening on ovarian cancer mortality: the prostate, lung, colorectal and ovarian (PLCO) Cancer screening randomized controlled trial, JAMA 305 (2011) 2295-2303.

[24] I. Jacobs, U. Menon, A. Ryan, A. Gentry-Maharaj, M. Burnell, J.K. Kalsi, et al., Ovarian cancer screening and mortality in the UK collaborative trial of ovarian cancer screening (UKCTOCS): a randomised controlled trial, Lancet 387 (2016) 945-956.

[25] P. Watson, R. Bützow, H.T. Lynch, J.P. Mecklin, H.J. Järvinen, H.F. Vasen, et al., International collaborative group on HNPCC. The clinical features of ovarian cancer in hereditary nonpolyposis colorectal cancer, Gynecol. Oncol. 82 (2001) 223-228.

[26] Z. Ketabi, K. Bartuma, I. Bernstein, S. Malander, H. Grönberg, E. Björck, et al., Ovarian cancer linked to Lynch syndrome typically presents as early-onset, non-serous epithelial tumors, Gynecol. Oncol. 121 (2011) 462-465.

[27] A. Niskakoski, S. Kaur, L. Renkonen-Sinisalo, H. Lassus, H.J. Järvinen, J.P. Mecklin, et al., Distinct molecular profiles in Lynch syndrome-associated and sporadic ovarian carcinomas, Int. J. Cancer 133 (2013) 2596-2608.

[28] http://www.STOET.nl, accessed 10 April 2017.

[29] http://www.oncoline.nl/erfelijke darmkanker, 2015.

[30] E.M. Grindedal, I. Blanco, A. Stormorken, L. Maehle, N. Clark, S. Gonzalez, et al., High risk of endometrial cancer in colorectal cancer kindred is pathognomonic for MMR mutation carriers, Familial Cancer 8 (2009) 145-151.

[31] N. Mavaddat, D. Barrowdale, I.L. Andrulis, S.M. Domchek, D. Eccles, H. Nevanlinna, et al., Pathology of breast and ovarian cancers among BRCA1 and BRCA2 mutation carriers: results from the consortium of investigators of modifiers of BRCA1/2 (CIMBA), Cancer Epidemiol. Biomark. Prev. 21 (1) (2012) 134-147.

[32] E.M. Grindedal, L. Renkonen-Sinisalo, H. Vasen, G. Evans, P. Sala, I. Blanco, et al., Survival in women with MMR mutations and ovarian cancer: a multicentre study in Lynch syndrome kindreds, J. Med. Genet. 47 (2) (2010) 99-102.

[33] H.A. Risch, J.R. McLaughlin, D.E. David, B. Rosen, L. Bradley, E. Kwan, et al., Prevalence and penetrance of germline BRCA1 and BRCA2 mutations in a population series of 649 women with ovarian cancer, Am. J. Hum. Genet. 68 (2001) 700-710.

[34] V. Bonadona, B. Bonaïti, S. Olschwang, S. Grandjouan, L. Huiart, M. Longy, et al., French cancer genetics network. Cancer risks associated with germline mutations in MLH1, MSH2, and MSH6 genes in Lynch syndrome, JAMA 305 (2011) 2304-2310.

[35] M.J. Casey, C. Bewtra, H.T. Lynch, C. Snyder, M. Stacy, P. Watson, Phenotypic heterogeneity of hereditary gynecologic cancers: a report from the Creighton hereditary cancer registry, Familial Cancer 12 (2013) 719-740.

[36] D.G. Evans, K.N. Gaarenstroom, D. Stirling, A. Shenton, L. Maehle, A. Dørum, et al, Screening for familial ovarian cancer: poor survival of BRCA1/2 related cancers, J. Med. Genet. 46 (2009) 593-597.

[37] R.L. Huang C.F. Chao, D.C. Ding C.P. Yu, C.C. Chang, H.C. Lai, et al, Multiple epithelia and nonepithelial tumors in hereditary nonpolyposis colorectal cancer: characterization of germline and somatic mutations of the MSH2 gene and heterogeneity of replication error phenotypes, Cancer Genet. Cytogenet. 153 (2004) 108-114.

[38] H.J. Järvinen, L. Renkonen-Sinisalo, K. Aktán-Collán, P. Peltomäki, L.A. Aaltonen, J.P. Mecklin, Ten years after mutation testing for Lynch syndrome: cancer incidence and outcome in mutation-positive and mutation-negative family members, J. Clin. Oncol. 27 (2009) 4793-4797.

[39] Z. Ketabi, A.M. Gerdes, B. Mosgaard, S. Ladelund, I. Bernstein, The results of gynecologic surveillance in families with hereditary nonpolyposis colorectal cancer. Gynecol. Oncol. 133 (2014) 526.

[40] K.M. Schmeler, H.T. Lynch, L.M. Chen, M.F. Munsell, P.T. Soliman, M.B. Clark, et al., Prophylactic surgery to reduce the risk of gynecologic cancers in the Lynch syndrome, N. Engl. J. Med. 354 (2006) 261-269. 